\title{
An Amino Acid Substitution in the Human Intestinal Fatty Acid Binding Protein Is Associated with Increased Fatty Acid Binding, Increased Fat Oxidation, and Insulin Resistance
}

\author{
Leslie J. Baier, ${ }^{\star}$ James C. Sacchettini, ${ }^{\ddagger}$ William C. Knowler, ${ }^{\star}$ Janina Eads, ${ }^{\ddagger}$ Giuseppe Paolisso, ${ }^{\star}$ Pietro A. Tataranni, ${ }^{\star}$ \\ Hisayoshi Mochizuki, ${ }^{\star}$ Peter H. Bennett, ${ }^{\star}$ Clifton Bogardus, ${ }^{\star}$ and Michal Prochazka \\ *Phoenix Epidemiology and Clinical Research Branch, National Institute of Diabetes and Digestive and Kidney Diseases, \\ National Institutes of Health, Phoenix, Arizona 85016; and Department of Biochemistry, Albert Einstein College of Medicine, \\ Bronx, New York 10461
}

\begin{abstract}
The intestinal fatty acid binding protein locus (FABP2) was investigated as a possible genetic factor in determining insulin action in the Pima Indian population. A polymorphism at codon 54 of FABP2 was identified that results in an alanineencoding allele (frequency 0.71 ) and a threonine-encoding allele (frequency 0.29). Pimas who were homozygous or heterozygous for the threonine-encoding allele were found to have a higher mean fasting plasma insulin concentration, a lower mean insulin-stimulated glucose uptake rate, a higher mean insulin response to oral glucose and a mixed meal, and a higher mean fat oxidation rate compared with Pimas who were homozygous for the alanine-encoding allele. Since the FABP2 threonine-encoding allele was found to be associated with insulin resistance and increased fat oxidation in vivo, we further analyzed the FABP2 gene products for potential functional differences. Titration microcalorimetry studies with purified recombinant protein showed that the threonine-containing protein had a twofold greater affinity for long-chain fatty acids than the alanine-containing protein. We conclude that the threonine-containing protein may increase absorption and/or processing of dietary fatty acids by the intestine and thereby increase fat oxidation, which has been shown to reduce insulin action. (J. Clin. Invest. 1995. 95:1281-1287.) Key words: insulin resistance • fatty acid binding protein - non-insulin-dependent diabetes mellitus • fat oxidation • genetic polymorphism
\end{abstract}

\section{Introduction}

The Pima Indians of Arizona have the highest reported prevalence of non-insulin-dependent diabetes mellitus (NIDDM) ${ }^{1}$ of any population in the world; more than half of the population over $35 \mathrm{yr}$ of age has the disease (1). Insulin resistance is a major risk factor for NIDDM in the Pimas (2) as well as in

Address correspondence to Dr. Leslie J. Baier, Phoenix Epidemiology and Clinical Research Branch, National Institute of Diabetes and Digestive and Kidney Diseases, National Institutes of Health, 4212 N. 16th Street, Phoenix, AZ 85016.

Received for publication 8 June 1994 and in revised form 20 October 1994

1. Abbreviations used in this paper: IFABP, intestinal fatty acid binding protein; SSCP, single-stranded conformational polymorphism.

The Journal of Clinical Investigation, Inc.

Volume 95, March 1995, 1281-1287 caucasians (3). In both populations, insulin action varies widely, and a considerable portion of that variance is not due to individual differences in degree of obesity $(4,5)$. Insulin resistance has also been shown to aggregate in families, in both caucasians (4) and Pimas (5), and a recent segregation analysis in caucasian pedigrees suggested that a major gene locus may be the cause of this familial effect (6). In addition, a study of caucasian monozygotic and dizygotic twins indicated that insulin action in vivo has major heritable determinants (7).

We have previously reported linkage between measures of insulin action in Pimas ( fasting insulin concentrations and maximal insulin-stimulated glucose uptake ) and a region on chromosome $4 \mathrm{q}$ near the FABP2 locus ( 8 ). The FABP2 gene encodes the intestinal fatty acid binding protein, IFABP, which is a member of a family of intracellular lipid binding proteins. The $15-\mathrm{kD}$ IFABP is expressed only in the columnar absorptive epithelial cells (enterocytes) of the small intestine villus. This protein contains a single ligand binding site that displays a high affinity for both saturated and unsaturated long-chain fatty acids (9). Since fatty acid metabolism has historically been linked to insulin resistance (10), FABP2 was analyzed as a candidate gene for determining insulin action. A polymorphism that altered the coding sequence for the FABP2 protein product was identified. This polymorphism was found to be associated with insulin resistance and increased fat oxidation rates in vivo and with increased binding affinities for long-chain fatty acids in vitro.

\section{Methods}

Subjects studied as outpatients. These subjects were a subset of the population of Pimas that are participating in our ongoing epidemiologic study of the Gila River Indian Community (1). The selection criteria for this subset included the following ( $a$ ) full-heritage Pima or Tohono O'odham, or a mixture of these two closely related tribes $(b)$ examined at least once after the age of $35 \mathrm{yr}$, and $(c)$ resided in the community for at least $4 \mathrm{yr}$. There were 760 subjects who met the selection criteria. Some subjects in this group were siblings or otherwise related. As part of their outpatient examination, each subject had an oral glucose tolerance test for determination of diabetic status (11) and determination of plasma glucose and insulin concentrations $2 \mathrm{~h}$ after ingesting $75 \mathrm{~g}$ of glucose. Of these 760 subjects, 476 were diabetic, 280 were nondiabetic, and 4 were of unknown diabetic status at their last examination. Plasma insulin and glucose concentrations from the oral glucose tolerance test were available from a nondiabetic exam on 457 of these subjects. These subjects included the 280 subjects who were nondiabetic at their last exam and an additional 177 subjects on whom data were available before they became diabetic.

Inpatient studies. These subjects were a subset of our inpatient study group who were admitted to our metabolic ward as part of a prospective study of metabolic risk factors for NIDDM (2). The criteria for selection 
included the following: ( $a$ ) full-heritage Pima or Tohono O'odham, or a mixture of the two, $(b)$ the most obese person (largest body mass index) from each nuclear family studied, i.e., no subject was a firstdegree relative of another, and $(c)$ availability of results from a hyperinsulinemic, euglycemic clamp study when the individual was not diabetic. There were 137 subjects who met these criteria. Each of these subjects had been admitted to the clinical research ward for $\sim 7-10 \mathrm{~d}$. After 2$3 \mathrm{~d}$, they underwent several metabolic studies including underwater weighing to determine body composition (5); a 3-h oral glucose tolerance test; a standard mixed meal test; and a two-step, hyperinsulinemic, euglycemic clamp study with simultaneous infusion of tracer amounts of tritiated glucose to estimate rates of hepatic glucose production and with indirect calorimetry to estimate substrate oxidation rates.

Insulin response to oral glucose and a mixed meal. Blood samples, for determination of plasma glucose and insulin responses, were drawn over a period of $2 \mathrm{~h}(0,30,60$, and $120 \mathrm{~min})$ after ingestion of $75 \mathrm{~g}$ of glucose and for $4 \mathrm{~h}(0,30,60,90,120,150,180$, and $240 \mathrm{~min})$ after a mixed meal. Glucose and insulin responses above fasting concentrations were determined using a trapezoidal method. The mixed meal was eaten over $20 \mathrm{~min}$ in the morning, preceded by a 10 -h overnight fast. The meal was $30 \%$ of the weight maintenance calories and was comprised of $\sim 20 \%$ protein, $40 \%$ carbohydrate, and $40 \%$ fat.

Hyperinsulinemic, euglycemic clamp. This test has been described in detail elsewhere $(5,12)$. Briefly, after a 10 -h overnight fast, a primed, continuous infusion of tritiated glucose was begun and continued until the end of the study. After $2 \mathrm{~h}$, a primed, continuous $\left(40 \mathrm{mU} / \mathrm{m}^{2}\right.$ per min) insulin infusion was given for $100 \mathrm{~min}$, and the rate of exogenous glucose infusion and the tritiated glucose specific activity were used to calculate the mean rate of glucose uptake during the last $40 \mathrm{~min}$ of the insulin infusion as described $(5,12)$. Glucose uptake rates were normalized to the estimated metabolic body size (12).

Indirect calorimetry. $1 \mathrm{~h}$ before the start of the insulin infusion, a clear plastic ventilated hood was placed over each subject's head. Room air was drawn through the hood at a measured rate of flow, and a constant fraction of expired air was withdrawn and analyzed for oxygen and carbon dioxide context (Applied Electrochemical Analyzers, Sunnyvale, CA). Continuous, integrated calorimetric measurements were made every $5 \mathrm{~min}$, for $40 \mathrm{~min}$. Protein oxidation rates were estimated from the urinary area production rate. The nonprotein respiratory quotient was then calculated, and the substrate oxidation rate was determined from the equations of Lusk (13) for the last $20 \mathrm{~min}$ of the measurement period.

Structural analysis of the FABP2 gene. Genomic DNA from 41 Pimas was used to screen for structural variations in the FABP2 gene. Based on our previous finding of an association of FABP2 microsatellite $\left(\mathrm{ATT}_{n}\right.$ repeat element) allele 1 with insulin sensitivity and allele 3 with insulin resistance (8), we selected DNA from nondiabetic Pima Indians who were either homozygous for allele 1 and insulin sensitive $(N=12)$, or homozygous for allele 3 and insulin resistant $(N=29)$. None of these subjects were first-degree relatives among themselves. Singlestranded conformational polymorphism (SSCP) analysis was used to screen for nucleotide variability in the four exons of FABP2. Each of the four exons of FABP2 was initially amplified by PCR from genomic DNA using primers that were designed from noncoding sequences flanking each exon (14). Primer sequences $\left(5^{\prime}\right.$ to $\left.3^{\prime}\right)$ were as follows: FEX-1S (sense) = CAAGGACAGACCTGAATCTCT and FEX-1A $($ antisense $)=$ ATGTTTGTAAGAAAGCAAAGAATG for exon 1 (product size $167 \mathrm{bp}$ ); FEX-2S = CACTTCCTATGGGATTTGACT and FEX-2A = TTGGGTAGAAAAATCAAGAATG for exon 2 (product size 274 bp); FEX-3S = TGTAAGACCCTAATAAATGCC and FEX-3A = TGTTTTGTAGTAATTTTTGCCTTT for exon 3 (product size 227 bp); FEX4S = ACTTAGATGTAAACCTTAAAGAT and FEX-4A = ATAGATCTTCTGTCCAATTTG for exon 4 (product size $137 \mathrm{bp}$ ). For the PCR, DNA samples (30 ng) were amplified in a 5$\mu 1$ volume consisting of $1 \times$ PCR buffer (Perkin-Elmer Corp., Norwalk, CT) containing $1.5 \mathrm{mM} \mathrm{MgCl} 2,0.2 \mathrm{mM}$ each dNTP, 3 pmol of each primer, and $0.125 \mathrm{U}$ of AmpliTaq (Perkin-Elmer). Amplifications were performed for 27 cycles in a GeneAmp 9600 cycler (Perkin-Elmer),
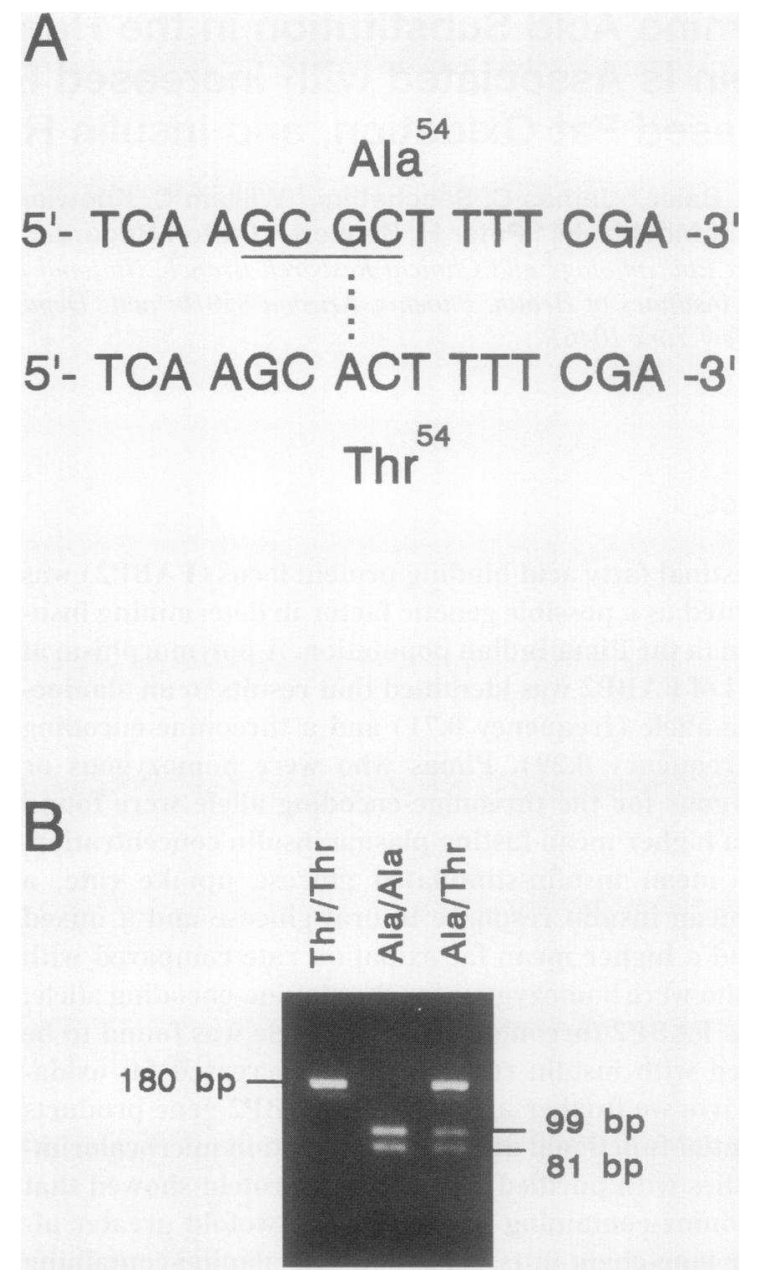

Figure 1. A Hhal RFLP in exon 2 of FABP2. The frequencies of the Ala54- and Thr54-encoding FABP2 alleles were determined by typing the HhaI RFLP in DNA samples from 760 Pimas. $(A)$ The nucleotide sequence of a segment of exon 2 containing the Ala54-coding allele (top) and the Thr54-coding allele (bottom). The G to A substitution is indicated by a vertical dotted line. The Hhal recognition site is underlined. ( $B$ ) Restriction patterns of exon 2 digested with HhaI. PCR products from alleles with $\mathrm{Thr} 54$ (lacking the $\mathrm{HhaI}$ recognition site) migrate as 180-bp fragments; those from alleles with Ala54 (containing the Hhal site) are cleaved into 99- and 81-bp fragments. DNA amplified from individuals heterozygous for both alleles shows all three fragments.

and each cycle consisted of $45 \mathrm{~s}$ at $94^{\circ} \mathrm{C}, 60 \mathrm{~s}$ at $55^{\circ} \mathrm{C}$, and $45 \mathrm{~s}$ at $72^{\circ} \mathrm{C}$, followed by a 5 -min extension at $72^{\circ} \mathrm{C}$. To each PCR sample, 5 $\mu \mathrm{l}$ of $1 \times$ PCR buffer was added containing $0.1 \mathrm{U}$ of AmpliTaq and $15 \mathrm{pmol}$ of each primer labeled with [ $\left.\gamma^{32} \mathrm{P}\right] \mathrm{ATP}$, and an additional amplification cycle was performed. The labeled PCR products were then analyzed by SSCP electrophoretic techniques. For SSCP, DNA samples were diluted with $3 \mathrm{vol}$ of sequencing dye, heat denatured, and electrophoresed in $0.5 \times$ TBE running buffer at room temperature (constant power of $5 \mathrm{~W}$ ) through $5 \%$ polyacrylamide gels (acrylamide/bis = 75:1) with and without 5\% glycerol. Mobility shifts were visualized by autoradiography. DNA fragments that demonstrated mobility shifts were sequenced directly by the dsDNA Cycle Sequencing System (Gibco BRL, Gaithersburg, MD).

To screen for large deletions or rearrangements of the FABP2 gene, DNA was digested with EcoRI and SacI and analyzed by Southern blot techniques, as described elsewhere (15).

Determination of the frequency of the $G$ to A nucleotide substitution 
Table I. Characteristics of Nondiabetic Pima Indians with Ala54- or Thr54-encoding FABP2 Alleles

\begin{tabular}{|c|c|c|c|c|}
\hline & $\begin{array}{l}\text { Ala54 homozygotes mean } \\
\text { ( } 95 \% \text { confidence interval) }\end{array}$ & $\begin{array}{l}\text { Ala54/Thr54 heterozygotes mean } \\
\text { (95\% confidence interval) }\end{array}$ & $\begin{array}{l}\text { Thr54 homozygotes mean } \\
\text { ( } 95 \% \text { confidence interval) }\end{array}$ & $P$ \\
\hline $\operatorname{Sex} M / F$ & $40 / 28$ & $28 / 29$ & $7 / 5$ & NS \\
\hline Age $(y r)$ & $30(28,31)$ & $31(28,32)$ & $31(27,34)$ & NS \\
\hline Weight (kg) & $99.0(93.5,104.4)$ & $95.9(90.8,100.9)$ & $103.2(88.4,118.0)$ & NS \\
\hline Body fat $(\%)$ & $35(33,36)$ & $34(32,36)$ & $34(30,39)$ & NS \\
\hline Fasting glucose $(\mathrm{mg} / 100 \mathrm{ml})$ & $93(91,95)$ & $95(93,97)$ & $91(86,95)$ & NS \\
\hline Fasting insulin $(\mu \mathrm{U} / \mathrm{ml})$ & $37(34,41)$ & $41(37,46)$ & $43(32,56)$ & $<0.04$ \\
\hline Fasting fat oxidation (mg/min per kg MBS) & $0.61(0.56,0.67)$ & $0.72(0.66,0.78)$ & $0.72(0.53,0.89)$ & $<0.002$ \\
\hline \multicolumn{5}{|l|}{ Hyperinsulinemic, euglycemic clamp } \\
\hline Glucose $(\mathrm{mg} / 100 \mathrm{ml})$ & $96(94,97)$ & $97(95,99)$ & $95(92,99)$ & NS \\
\hline Insulin $(\mu \mathrm{U} / \mathrm{ml})$ & $143(134,153)$ & $147(138,157)$ & $163(139,190)$ & NS \\
\hline Glucose uptake (mg/min per kg MBS) $\ddagger$ & $2.70(2.52,2.88)$ & $2.49(2.29,2.69)$ & $2.40(2.18,2.62)$ & $<0.04$ \\
\hline
\end{tabular}

Statistical analyses were performed after pooling the Thr54 homozygotes with heterozygotes and comparing this group with the Ala54 homozygotes. Gender ratio was tested by chi-square analysis. Insulin values were compared after $\log _{10}$ transformation. Weight and body fat were compared after adjusting for gender, and fasting glucose concentrations and lipid oxidation rates were compared after adjusting for body fat, age, and sex using linear regression analysis. Fasting insulin concentrations were also adjusted for the simultaneously measured glucose concentrations. Fat oxidation rates were available on ALA54 homozygotes $(39 \mathrm{M} / 24 \mathrm{~F})$, heterozygotes $(36 \mathrm{M} / 27 \mathrm{~F})$, and Thr54 homozygotes $(7 \mathrm{M} / 5 \mathrm{~F})$. * Geometric means are given for insulin concentrations. $\ddagger$ MBS-metabolic body size.

in exon 2 of $F A B P 2$. The frequency of the $\mathrm{G}$ to $\mathrm{A}$ polymorphism found in exon 2 of FABP2 was determined in the 760 Pimas studied as outpatients and in a sample of 56 unrelated caucasians. The caucasian DNAs were obtained from the National Institute of General Medical Sciences, Human Mutant Cell Repository, Coriell Institute, Camden, NJ.

This $\mathrm{G}$ to A substitution disrupts the sequence of the unique Hhal restriction site in exon 2 . Therefore, this RFLP was analyzed to rapidly screen the subjects for the $G$ or A polymorphism. Exon 2 was PCR amplified from $200 \mathrm{ng}$ of genomic DNA in a $20-\mu$ l volume with the primers 5'-ACAGGTGTTAATATAGTGAAAAG-3' and 5'-TACCCTGAGTTCAGTTCCGTC- $3^{\prime}$. The conditions were as described for SSCP except that the $\mathrm{MgCl}_{2}$ concentration was $2.5 \mathrm{mM}$. Amplified exon 2 DNAs were digested with $\mathrm{Hhal}$ and separated through a $4 \%$ agarose gel (NuSieve GTG, FMC Bioproducts, Rockland, ME). PCR products that lacked the HhaI site migrated as 180 -bp fragments, whereas PCR products containing an intact HhaI site are cleaved into 99 - and 81 -bp fragments. Direct sequencing of DNA from 25 Pimas who were not first-degree relatives confirmed that the loss of the Hhal site was consistently caused by the same $G$ to A substitution.

Statistical analyses. Because so few subjects were homozygous for the FABP2 Thr54 allele, the data from these subjects were pooled with the heterozygotes for statistical comparison with the FABP2 Ala54 homozygotes. Comparisons of phenotypes between these groups were performed after adjusting for covariants by linear regression analyses using the general linear modeling procedure of SAS (Statistical Analyses Systems; SAS Inst., Cary, NC).

Isolation, mutagenesis, and expression of IFABP cDNA. Total mRNA, isolated from human Caucasian jejunum tissue, was reverse transcribed using an oligo(dT) primer, and IFABP cDNA was specifically amplified by PCR using the oligonucleotide primers: forward 5 'CTCAACTGAAACCATGGCGTTTGAC- ${ }^{\prime}$ ' and reverse $5^{\prime}$-CGCCAAGAGGATCCTTAATCC-3'. The 400-bp PCR product was digested with $\mathrm{Ncol}$ and $\mathrm{BamHI}$ and cloned into the $\mathrm{Ncol}$ and BamHI sites of the expression plasmid pET-3D (Novagen, Madison WI). The IFABP cDNA insert was sequenced using the dsDNA cycle sequencing kit (Gibco BRL) and was identical to the published human IFABP sequence including codon 54 (GCT) encoding alanine (14). The IFABP-Ala cDNA was used as a template for PCR primer mismatch site-directed mutagenesis to synthesize the cDNA for IFABP-Thr. The 5' region ( $180 \mathrm{bp}$ ) of the cDNA encoding IFABP-Thr was amplified, using the forward primer previously described with the reverse primer 5 '-TTC-
AATGTTTCGAAAAGTGCTTG- $3{ }^{\prime}$. The reverse primer has a single base mismatch that introduced a $G$ to $A$ substitution at nucleotide 160 of the coding strand of the amplified sequence. The 180-bp PCR product was digested with $\mathrm{NcoI}$ and $\mathrm{NspV}$ and swapped with the NcoI-NspV fragment of the IFABP-Ala/pET plasmid to create an IFABP-Thr/pET plasmid. The cDNA sequence of IFABP-Thr was also confirmed by dsDNA cycle sequencing. BL21 cells (Novagen) were transformed with the IFABP-Ala/pET-3d plasmid or the IFABP-Thr/pET-3d plasmid. IFABP production was induced with $0.4 \mathrm{mM}$ isopropyl- $\beta$-D-thiogalactopyranoside for $2 \mathrm{~h}$, and IFABP was purified to homogeneity as described (16). Endogenous Escherichia coli fatty acids that remained bound to the protein after purification were removed by passage through hydroxyalkoxypropyl dextran (Lipidex 1000, type VI; Sigma Chemical Co., St. Louis, MO).

Titration microcalorimetry. Titration microcalorimetry was performed using a differential titrating calorimeter (OMEGA; MicroCal. Inc., Northampton, MA). Titrations were done as described (17), with the modifications that $25,4-\mu$ l aliquots of either arachidonate or oleate ( $2.37 \mathrm{mM}$ in $20 \mathrm{mM}$ Tris buffer, $\mathrm{pH} 8$ ) were injected into $1.4 \mathrm{ml}$ of the protein sample ( $50 \mu \mathrm{M}$ IFABP in Tris buffer, $\mathrm{pH} 8$ ), to a final fatty acid/protein mole ratio $>1$. All titrations were at $37^{\circ} \mathrm{C}$ with constant mixing at $350 \mathrm{rpm}$. The heat of the binding reaction of arachidonate and oleate to each IFABP was measured by three different titrations, using two separate protein preparations each of IFABP-Ala and IFABPThr. Data were processed using computer software (Origin; MicroCal. Inc., Northampton, MA). A function that modeled one class of independent binding sites was used to fit the data. The association and dissociation constants, molar binding stoichiometry, and enthalpy were determined from the fitted curve.

\section{Results}

Detection of an alanine to threonine substitution in the coding sequence of $F A B P 2$. No large deletions or rearrangements in the FABP2 gene were detected by Southern blot analysis of DNAs digested with EcoRI or SacI, but a RFLP was observed with EcoRI ( $9 / 12 \mathrm{~kb})$. However, since the entire FABP2 gene spans $<4-\mathrm{kb}$ and has no recognition sequence for this endonuclease, we conclude that this RFLP was caused by a variation at an EcoRI site outside the boundaries of this locus. 
SSCP analysis, followed by direct sequencing of exons that demonstrated altered mobility by SSCP, identified three frequent single-nucleotide substitutions in the FABP2 exons. Two of the nucleotide substitutions ( $\mathrm{C}$ to $\mathrm{T}$ in codon 71 and $\mathrm{G}$ to $\mathrm{A}$ in codon 118) were silent polymorphisms. The third singlebase substitution ( $\mathrm{G}$ to $\mathrm{A}$ in codon 54 in exon 2 ) predicted an amino acid change from alanine to threonine and resulted in the loss of a single Hhal restriction site in this exon (Fig. 1). The frequencies of the alanine-encoding (Ala54) and threonineencoding (Thr54) FABP2 alleles were determined to be 0.71 and 0.29 , respectively, in 760 Pimas. Similar frequencies $(0.69$ and 0.31 ) were observed in 56 caucasian DNA samples. The frequencies of the Ala54 and Thr54 alleles were not significantly different in diabetic versus nondiabetic Pimas. Diabetics $(n$ $=476$ ) had frequencies of 0.72 and 0.28 and nondiabetics $(n$ $=280$ ) had frequencies of 0.69 and 0.31 for the Ala54 and Thr54 alleles, respectively.

The threonine-encoding allele is associated with insulin resistance and increased fat oxidation rates. Since only a few subjects were homozygous for the Thr54 allele $(N=32)$, data from the Thr 54 homozygotes were pooled with data from the Thr54/Ala54 heterozygotes $(N=207)$ for statistical comparisons with data from the Ala54 homozygotes $(N=218)$. In the 457 nondiabetic Pimas studied as outpatients, the Thr54 homozygotes had a higher mean 2-h plasma insulin concentration during the oral glucose tolerance test compared with the mean of those with the Ala54 allele (geometric means $=167$. 162, and 145 for Thr54/Thr5, Thr54/Ala54, and Ala54/Ala54 genotypes, respectively). These values differed significantly ( $P$ $<0.04$ ) after adjusting for age, body mass index, and sex and simultaneously measured glucose concentrations.

In the 137 nondiabetic Pimas studied as inpatients, the Thr54 heterozygotes and homozygotes had a higher mean fasting insulin concentration, a lower mean insulin-stimulated glucose uptake rate during the euglycemic clamp, a higher fasting rate of fat oxidation (Table I), and a higher mean insulin response to oral glucose and a mixed meal. compared with the Ala54 homozygotes (Fig. 2 ).

The threonine-containing protein has a higher affinity for long-chain fatty acids. Since a functional property of IFABP is to bind long-chain fatty acids ( $\mathrm{C} 16-\mathrm{C} 20)$, we analyzed purified recombinant IFABP-Ala and IFABP-Thr proteins by titration microcalorimetry to quantitate their respective binding affinities for oleate (C18:1) and arachidonate (C20:4) (Fig. $3 A$ and $B$ ). Based on the heat of reaction given off by the fatty acid binding to the protein, the dissociation constants for oleate and arachidonate binding to IFABP-Ala were calculated to be 381 and 380 $\mathrm{nM}$, respectively; those for oleate and arachidonate binding to IFABP-Thr were calculated to be 191 and $179 \mathrm{nM}$. respectively (Fig. $3 C$ ). The enthalpies of binding $(\triangle \mathrm{H})$ were also larger for the IFABP-Thr protein, as compared with the IFABP-Ala. for binding to oleate and arachidonate.

\section{Discussion}

The intestinal fatty acid binding protein locus, FABP2, was investigated as a possible genetic factor in determining variance in insulin action in Pima Indians. A relatively common $(\sim 30 \%)$ base substitution in the coding sequence was found that encodes an amino acid substitution (Ala54 $\rightarrow$ Thr54) in the protein. In vitro, the Thr54-containing protein had a twofold greater affinity for long-chain fatty acids than the Ala54-containing protein. In

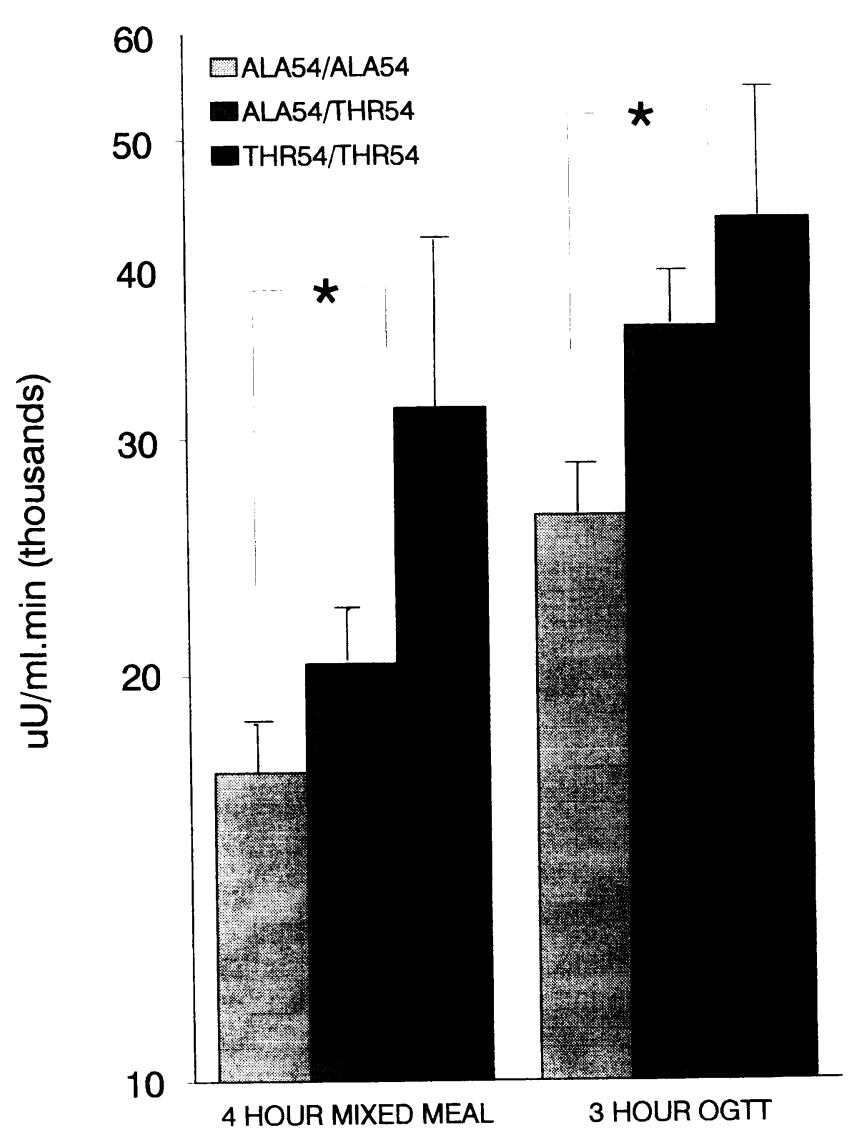

Figure 2. Insulin responses to a 4 -h mixed meal and a $3-\mathrm{h}, 75-\mathrm{g}$ oral glucose tolerance test. Means and $1 \mathrm{SE}$ of insulin areas above fasting concentrations are given for subjects homozygous for the Ala54 allele $(N=68)$, heterozygous for the Ala54/Thr54 alleles $(N=57)$, or homozygous for the Thr54 allele $(N=12)$. * $P<0.05$ comparing Ala54 homozygous subjects with subjects homozygous or heterozygous for Thr54, after adjusting for glucose concentrations, body fat, age, and sex using linear regression analysis. Insulin values were compared after $\log _{11}$ transformation. Mean glucose areas after the mixed meal were not significantly different among the groups, but mean glucose area above fasting was higher in subjects with a Thr54 allele compared with Ala54 homozygotes ( $P<0.05$ ) after adjusting for body fat. age, and sex.

a large group of nondiabetic Pimas studied as outpatients, those having the Thr54 allele were more hyperinsulinemic 2 -h after ingestion of glucose than those homozygous for the Ala54 allele. This suggested the Thr54 allele was associated with some degree of insulin resistance. This observation was confirmed and extended in more detailed inpatient studies on a smaller group of Pimas. In these studies, Pimas with the Thr54 allele were more hyperinsulinemic after oral glucose and a mixed meal and more insulin resistant by direct testing using the hyperinsulinemic, euglycemic clamp technique. In addition, subjects with the Thr54 allele had higher fasting rates of fat oxidation. These data are consistent with the hypothesis that the greater affinity of the Thr54 allele for long-chain fatty acids results in greater intestinal absorption of fatty acids, greater plasma lipid concentrations, and thereby, greater fat oxidation rates that inhibit insulin action in vivo. Although this is only a hypothesis, it is the simplest explanation for the data and is consistent with 


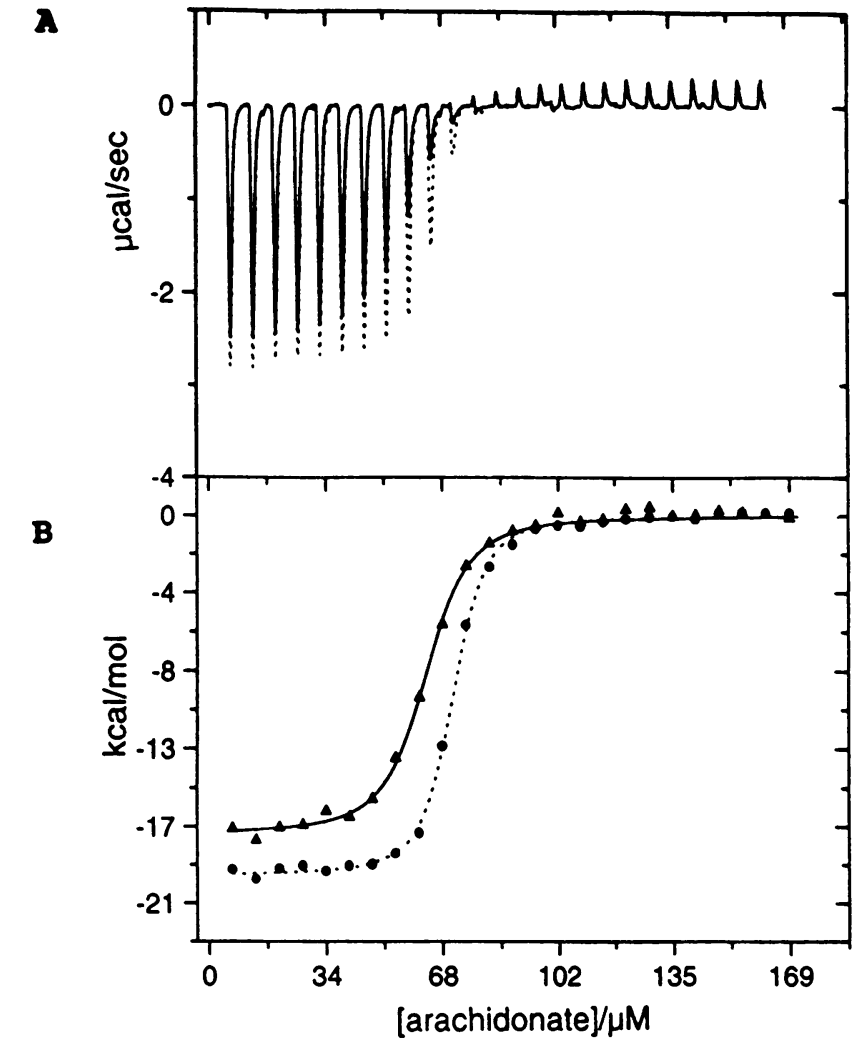

\begin{tabular}{lcccc}
\hline C & \multicolumn{2}{c}{ IFABP-Ala } & \multicolumn{2}{c}{ IFABP-Thr } \\
& $\mathrm{K}_{\mathrm{D}}(\mathrm{nM})$ & $\Delta \mathrm{H}\left(\mathrm{kcal}^{\left.-\mathrm{mol}^{-1}\right)}\right.$ & $\mathrm{K}_{\mathrm{D}}(\mathrm{nM})$ & $\Delta \mathrm{H}\left(\mathrm{kcal}^{\mathrm{m}} \mathrm{mol}^{-1)}\right.$ \\
Arachidonate & $380 \pm 50$ & $17.4 \pm .2$ & $179 \pm 29$ & $19.7 \pm .2$ \\
Oleate & $381 \pm 72$ & $13.4 \pm .2$ & $191 \pm 44$ & $14.6 \pm .4$ \\
& & & & \\
\hline
\end{tabular}

Figure 3. Titration microcalorimetry data for human IFABP binding to arachidonate (C20:4) and oleate (C18:1). (A) Titration isotherm for IFABP-Ala binding to arachidonate (solid line) super-imposed over titration isotherm for IFABP-Thr binding to arachidonate (dashed line). At each titration point, an aliquot of arachidonate was injected into the protein solution and the heat of the binding reaction was measured. $(B)$ Plot of binding enthalpy $(\triangle H$; $\mathrm{kcal} / \mathrm{mol}$ ) versus cummulative arachidonate concentration $\left(10^{-6} \mathrm{M}\right)$ for arachidonate binding to IFABPAla (triangles) and IFABP-Thr (circles). The data points represent the areas under each injection peak, after subtraction of a constant enthalpy value to account for the heat of buffer-buffer injections. The fitted curves are derived from a "one class of sites" model. $(C)$ The mean \pm SD for $K_{\mathrm{d}}$ and $\Delta \mathrm{H}$, from three experiments. what is currently known about the function of IFABP and the effect of fat oxidation on insulin action.

The crystal structure of rat IFABP as a holoprotein and an apoprotein (with and without bound fatty acid, respectively) has been determined (Fig. 4) (18). The tertiary structure of human and rat IFABP should be similar due to high sequence homology ( 108 of 132 residues are identical) (14). The major conformational adjustment between the apo- and holo- forms of IFABP occurs at the tight turn containing residues 54 and 55. The residues that form this turn adjust when long-chain fatty acids are bound to the protein. Therefore, even subtle changes in the properties of this turn could affect the structural properties of IFABP in such a way as to alter its overall stability, ligand specificity or affinity, or the kinetics of fatty acid acquisition/release. Since the alanine to threonine substitution at residue 54 is part of this critical turn, it is not surprising that the two forms of IFABP have different affinities for long-chain acids.

IFABP expression appears to be limited to the enterocytes of the small intestine, where it is extremely abundant, representing $2-3 \%$ of the total cytoplasmic mass (19). The restricted expression of this protein combined with its high affinity $(<1$ $\mu \mathrm{M}$ ) for both unsaturated and saturated long-chain fatty acids indicates that IFABP has a role in the absorption and intracellular transport of dietary long-chain fatty acids (9). The increased affinity of IFABP-Thr for long-chain fatty acids, compared with IFABP-Ala, could therefore be expected to increase the rate of uptake of dietary long-chain fatty acids. After absorption, most dietary fatty acids are converted into triglycerides, which leave the enterocyte in chylomicrons for delivery to peripheral tissues. Triglycerides are hydrolyzed by lipoprotein lipase in the capillaries, and the long-chain free fatty acids are locally oxidized or reesterified, or returned to the plasma. An increased rate of uptake of dietary fatty acids would increase triglyceride concentrations and result in an increased rate of fat oxidation in peripheral tissues.

As proposed by Randle et al. in 1963 (10), fatty acids and glucose compete as oxidative fuel sources in muscle, such that increased concentrations of fatty acids inhibit glucose uptake in muscle and result in insulin resistance. More specifically, Randle's "glucose-fatty-acid cycle" predicts the mechanism by which increased fat oxidation $(a)$ ultimately inhibits pyr- 


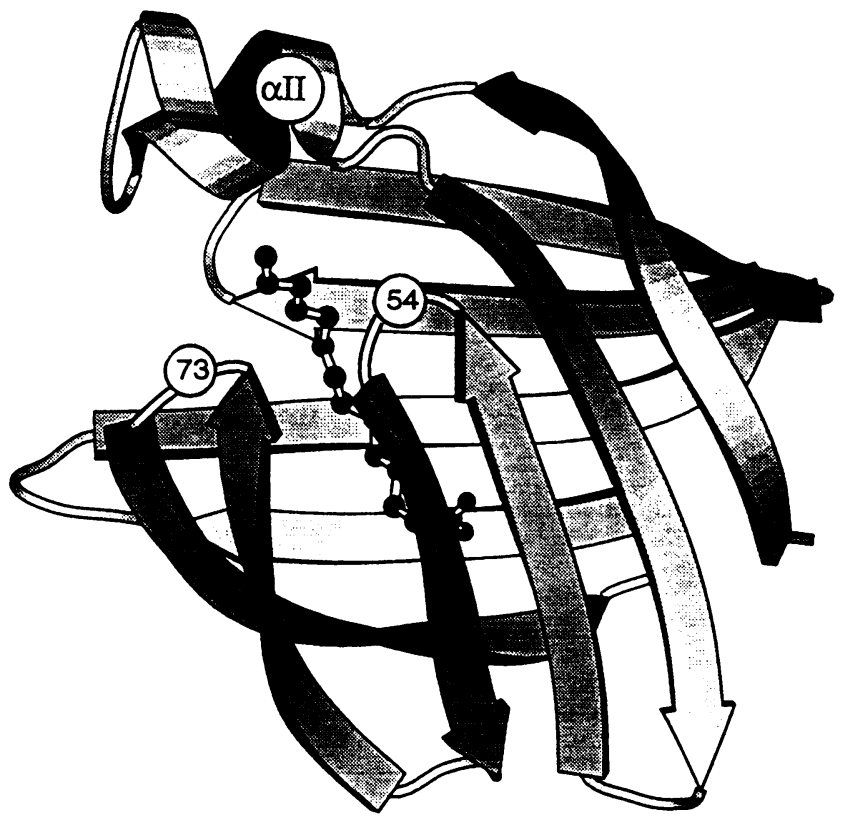

Figure 4. The structure of rat holo-IFABP. IFABP is composed of 10 anti-parallel $\beta$ strands, arranged into two nearly orthogonal $\beta$ sheets, and two short $\alpha$ helices. The bound fatty acid (shown as ball and stick model) inserts into a cavity between the $\beta$ sheets, with its carboxylate interacting with the guanidinium group of a buried arginine and its methylene chain extending toward the solvent-accessible opening. The opening to the cavity is defined by $\alpha$ helix II ( $\alpha$ II) and two sharp turns (residues 54-55 and 73-74). The alanine to threonine substitution occurs at residue 54 .

uvate dehydrogenase, which is the entry point for glucose (via pyruvate) into oxidative metabolism, and $(b)$ increases citrate levels, which inhibit glycolysis and cause a decrease in glucose uptake. Recently, Kelly et al. have confirmed the basis of Randle's theory by showing that increasing fat oxidation by elevating free fatty acid concentrations in vivo suppresses skeletal muscle glucose uptake by $25 \%$ and pyruvate dehydrogenase activity by nearly $50 \%$ during hyperinsulinemia (20). Increased fat oxidation rates are also associated with decreased rates of insulin-stimulated nonoxidative glucose uptake (21-23), and conversely, agents that decrease plasma fatty acid concentrations and fat oxidation rates increase rates of insulin-stimulated glucose uptake $(24,25)$.

The data presented here have shown that the Thr54 allele has a greater affinity for long-chain fatty acids and is associated with higher fat oxidation and insulin resistance in Pimas. Experimental evidence supports a possible mechanism by which the IFABP-Thr variant causes an increase in absorption of dietary fatty acids, which would elevate plasma lipid concentrations and thereby increase fat oxidation rates which are known to inhibit insulin action. We are currently directly investigating whether subjects homozygous for the Thr54 allele absorb more long-chain fatty acids from their diet than subjects homozygous for the Ala54 allele.

From these association studies, it remains unknown whether the alanine to threonine substitution in the FABP2 gene product is the explanation for the previously reported linkage results between a region on chromosome $4 \mathrm{q}$ and insulin action. It is entirely possible that the identification of the FABP2 polymor- phism was serendipitous, and a yet unknown gene is responsible for the initial observation of linkage. However, we can conclude that the FABP2 Thr54 allele is associated with insulin resistance in the Pima population. Our data also suggest that the FABP2 polymorphism alone is not the cause of the greater prevalence of NIDDM and insulin resistance in Pimas, as compared with caucasians, since the frequency of the Thr54 allele is the same in caucasians and Pimas. It is also unlikely that IFABP-Thr is the major cause of variability in insulin action in the Pimas. The observed differences in insulin action between subjects with the Thr54 and Ala54 allele are not large. However, insulin action in vivo is probably determined by several genes in addition to being influenced by environmental factors. Whether there are multiple genetic determinants of insulin action in the Pimas, each of which has an effect similar to that of IFABP-Thr, or whether there is one major gene with a much greater effect on insulin action, remains to be determined.

Although insulin resistance is a major risk factor for NIDDM, we did not find an association of the IFABP-Thr allele with NIDDM in 760 Pimas. Similarly, a recent study of caucasians found no association between the FABP2 locus and NIDDM (26). This is not altogether surprising, however, since NIDDM is a polygenic disease that is also affected by nongenetic determinants. A single protein polymorphism that is significantly associated with a subphenotype of the disease, such as insulin resistance, could be unassociated with the full phenotype of NIDDM, owing to the complexity of factors that cause the disease. Possibly a significant association will be found between the FABP2 genotype and NIDDM when other genes that contribute to the disease are identified and can be controlled for.

In summary, we have found that the IFABP-Thr-encoding allele is associated with increased fat oxidation, hyperinsulinemia, and insulin resistance, even after adjusting for effects of obesity, and its protein product has a higher affinity for longchain fatty acids. It is possible that persons with the IFABPThr-encoding allele either absorb more long-chain fatty acids or absorb long-chain fatty acids at a more rapid rate, which results in increased fat oxidation and inhibition of insulin action on glucose metabolism. The clinical severity of the insulin resistance and its effect on daily glucose homeostasis would then depend on the dietary content of long-chain fatty acids. Since increased absorption of polyunsaturated long-chain $\omega-3$ fatty acids improves insulin sensitivity, whereas increased absorption of saturated long-chain fatty acids reduces insulin sensitivity, the particular fatty acids in the diet may also affect the severity of insulin resistance $(27,28)$. Therefore, the common IFABPThr polymorphism may potentially be more deleterious in individuals who consume a diet high in saturated long-chain fatty acids, which is characteristic of the modern, "Westernized" diet.

\section{Acknowledgments}

We thank Pam Thuillez, Nancy Riebow, and Tina $\mathrm{Xi}$ for excellent technical assistance; Carol Massengill, RN, Head Nurse, and the Nursing Staff for professional care of the volunteers; and the residents and leaders of the Gila River Indian Community for their cooperation and assistance.

\section{References}

1. Knowler, W. C.. D. J. Pettitt. M. F. Saad, and P. H. Bennett. 1990. Diabetes mellitus in the Pima Indians. Incidence, risk factor and pathogenesis. Diabetes/ Metab. Rev. 6:1-27. 
2. Lillioja, S., D. M. Mott, M. Spraul, R. Ferraro, J. E. Foley, E. Ravussin, W. C. Knowler, P. H. Bennett, and C. Bogardus. 1993. Insulin resistance and insulin secretory dysfunction as precursors of non-insulin dependent diabetes mellitus. N. Engl. J. Med. 329:1988-1992.

3. Martin, B. C., J. H. Warram, A. S. Krolewski, R. N. Bergman, J. S. Soeldner, and C. R. Kahn. 1992. Role of glucose and insulin resistance in development of type 2 diabetes mellitus: results of a 25-year follow-up study. Lancet. 340:925929.

4. Martin, B. C., J. H. Warram, B. Rosner, S. S. Rich, J. S. Soeldner, and A. S Krolewski. 1992. Familial clustering of insulin sensitivity. Diabetes. 41:850-854

5. Lillioja, S., D. M. Mott, J. K. Zawadzki, A. A. Young, W. G. H. Abbott, W. C. Knowler, P. H. Bennett, P. Moll, and C. Bogardus. 1987. In vivo insulin action is familial characteristic in nondiabetic Pima Indians. Diabetes. 36:13291335.

6. Schumacher, M. C., S. J. Hasstedt, S. C. Hunt, R. R. Williams, and S. C. Elbein. 1992. Major gene effect for insulin levels in familial NIDDM pedigrees. Diabetes. 41:416-423.

7. Hardin, D., L. Maianu, and J. Sorbel. 1994. Genetic factors are more important than environment in determining insulin sensitivity, muscle glucose content, and related metabolic factors in normal twins. Diabetes 43(Suppl 1):73a. (Abstr.)

8. Prochazka, M., S. Lillioja, J. F. Tait, W. C. Knowler, D. M. Mott, M. Spraul, P. H. Bennett, and C. Bogardus. 1993. Linkage of chromosomal marker on $4 \mathrm{q}$ with a putative gene determining maximal insulin action in Pima Indians. Diabetes. 42:514-519.

9. Lowe, J. B., J. C. Sacchettini, M. Laposata, J. J. McQuillan, and J. I. Gordon. 1987. Expression of rat intestinal fatty acid-binding protein in Escherichia coli. J. Biol. Chem. 2262:5931-5937.

10. Randle, P. J., C. N. Hales, P. B. Garland, and E. A. Newsholme. 1963. The glucose fatty-acid cycle: its role in insulin sensitivity and the metabolic disturbances of diabetes mellitus. Lancet. i:785-789.

11. WHO Study Group. 1985. Diabetes mellitus: report of a WHO Study Group. World Health Org. Tech. Rep. Ser. 727:9-17.

12. Lillioja, S., B. L. Nyomba, M. F. Saad, R. Ferraro, C. Castillo, P. H Bennett, and C. Bogardus. 1991. Exaggerated early insulin release and insulin resistance in a diabetes-prone population: a metabolic comparison of Pima Indians and Caucasians. J. Clin. Endocrinol. Metab. 73:866-876.

13. Lusk, G. 1924. Animal calorimetry. Analysis of oxidation of mixtures of carbohydrate and fat. J. Biol. Chem. 59:41-42.

14. Sweetser, D. A., E. H. Birkenmeier, I. J. Klisak, S. Zollman, R. S. Sparkes, T. Mohandas, A. J. Lusis, and J. I. Gordon. 1987. The human and rodent intestinal fatty acid binding protein genes: a comparative analysis of their structure, expression and linkage relationships. J. Biol. Chem. 262:16060-16071.

15. Sambrook, J., E. F. Fritsch, and T. Maniatis. 1989. Molecular Cloning A Laboratory Manual. Cold Spring Harbor Laboratory Press, Cold Spring Harbor, NY.
16. Sacchettini, J. C., L. J. Banaszak, and J. I. Gordon. 1990. Expression of rat intestinal fatty acid binding protein in $E$. coli and its subsequent structural analysis: a model system for studying the molecular details of fatty acid-protein interaction. Mol. Cell. Biol. 98:81-93.

17. Jakoby, M. G., K. R. Miller, J. J. Toner, A. Bauman, L. Cheng, E. $\mathrm{Li}$, and D. P. Cistola. 1993. Ligand-protein electrostatic interactions govern the specificity of retinol- and fatty acid-binding proteins. Biochemistry. 32:872-878.

18. Sacchettini, J. C., and J. I. Gordon. 1993. Rat intestinal fatty acid binding protein. J. Biol. Chem. 268:18399-18402.

19. Cohn, S. M., T. C. Simon, and K. A. Roth. 1992. Use of transgenic mice to map cis-acting elements in the intestinal fatty acid binding protein (Fabpi) that control cell lineage-specific and regional patterns of expression along the duodenal-colonic and crypt-villus axes of the gut epithelium. J. Cell Biol. 119:27-44.

20. Kelly, D. E., M. Mokan, J. A. Simoneau, and L. J. Mandarino. 1993. Interaction between glucose and free fatty acid metabolism in human skeletal muscle. J. Clin. Invest. 92:91-98.

21. Felley, C. P., E. M. Felley, G. D. van Melle, P. Frascarolo, E. Jequier, and J. P. Felber. 1989. Impairment of glucose disposal by infusion of triglycerides in humans: role of glycemia. Am. J. Physiol. 256:E747-E752.

22. Bonadonna, R. C., K. Zych, C. Boni, E. Ferrannini, and R. A. DeFronzo. 1989. Time dependence of the interaction between lipid and glucose in humans. Am. J. Physiol. 257:E49-E56.

23. Boden, G., F. Jadali, J. White, Y. Liang, M. Mozzoli, X. Chen, E. Coleman, and C. Smith. 1991. Effects of fat on insulin-stimulated carbohydrate metabolism in normal men. J. Clin. Invest. 88:960-966.

24. Felley, C. P., H. Kleiber, G. D. van Melle, P. Frascarolo, E. Jequier, and J. P. Felber. 1992. Resistance to insulin mediated glucose disposal in obese subjects; respective effects of lipid metabolism and glycemia. Int. J. Obes. 16:185-191.

25. Kleiber, H., R. Munger, D. Jallut, L. Tappy, C. Felley, A. Golay, P. Frascarolo, E. Jequier, and J. P. Felber. 1992. Interaction of lipid and carbohydrate metabolism after infusions of lipids or lipid lowering agents: lack of a direct relationship between free fatty acid concentrations and glucose disposal. Diabetes Metab. 18:84-90.

26. Humphreys, P., M. McCarthy, J. Tuomilehto, E. Tuomilehto-Wolf, I. Stratton, R. Morgan, A. Rees, D. Owens, J. Stengard, A. Nissinen, G. Hitman, R. C. Turner, and S. O'Rahilly. 1994. Chromosome 4q locus associated with insulin resistance in Pima Indians. Studies in three European NIDDM populations. Diabetes. 43:800-804.

27. Storlien, L. H., A. B. Jenkins, D. J. Chisholm, W. S. Pascoe, S. Khouri, and E. W. Kraegen. 1991. Influence of dietary fat composition on development of insulin resistance in rats. Diabetes. 40:280-289.

28. Popp-Snijders, C., J. A. Schouten, R. J. Heine, J. van der Meer, and E. A. van der Veen. 1987. Dietary supplementation of omega-3 polyunsaturated fatty acids improves insulin sensitivity in non-insulin dependent diabetes. Diabetes Res. 4:141-147 